\author{
José Claudinei Lombardi \\ Marcos Lima \\ (Orgs.)
}

\title{
EDUCAÇÃO E REVOLUÇÃO: AS REVOLUÇÕES NOS SÉCULOS XIX E XX E AS POSSIBILIDADES DE UMA NOVA EDUCAÇÃO \\ $1^{\mathrm{a}}$ Edição Eletrônica
}

Uberlândia / Minas Gerais

Navegando Publicações

2020

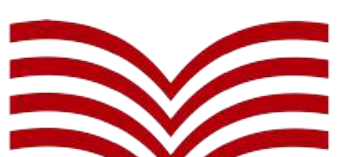

NAVEGANDO 


\title{
VIII
}

\section{A REVOLUÇÃO RUSSA E OS DESAFIOS À PEDAGOGIA HISTÓRICO-CRÍTICA ${ }^{*}$}

\author{
José Claudinei Lombardi
}

\section{Introdução}

O tema enseja que, neste momento de profunda crise estrutural do modo capitalista de produção e de aprofundamento da crise conjuntural brasileira, busquemos analisar as possibilidades da educação para o encontro de alternativas revolucionárias e transformadoras para tirar os homens (no sentido de "gênero humano", homem e mulher) do caminho da barbárie e da escravidão, recolocando na ordemdo-dia a possibilidade da revolução (como transformação estrutural da sociedade, como plena emancipação da humanidade), tema que considero plenamente vigoroso.

Como já expressei no estudo dos clássicos do marxismo e a educação (LOMBARDI, 2011), entendo que a escola tem um importante papel na educação dos trabalhadores, possibilitando o domínio das ferramentas teóricas para uma compreensão crítica do mundo, através do acesso aos saberes historicamente produzidos pela humanidade, condição elementar para assumir as rédeas do poder político.

\footnotetext{
${ }^{*}$ DOI - 10.29388/978-65-86678-06-2-f.175-200

1 Texto apresentado na mesa redonda "Revolução Russa e educação", ocorrida as 14:00 horas na Faculdade de Educação da Unicamp no dia 21 de setembro de 2017, numa promoção conjunto do HISTEDBR e FE Unicamp. Tive por objetivo colocar ênfase na importância da Revolução de Outubro no que diz respeito à educação e, pessoalmente, busquei tecer algumas breves reflexões da contribuição para a Pedagogia Histórico-Crítica. Publicado em: Germinal: Marxismo e Educação em Debate, Salvador, v. 9, n. 3, p. 292-306, dez. 2017. ISSN: 2175-5604 292
} 
Este artigo resulta de participação em mesa redonda, na Faculdade de Educação da Unicamp, comemorativa aos 100 anos da Revolução Russa, em conjunto com as Professoras Mariza Bittar e Nereide Saviani, duas intelectuais que tem contribuído, em diferentes oportunidades, com a reflexão sobre a temática. Tive oportunidade de expor minha posição sobre o tema em outro evento (LOMBARDI, 2017), não trazendo para esta mesa uma elaboração original ${ }^{2}$. Minha exposição retomará sinteticamente o tema, organizando-o em três pontos: 1 . O significado histórico da Revolução Russa; 2. A educação na Revolução de Outubro; 3. Observações pontuais sobre a educação na Rússia revolucionária e a Pedagogia Histórico-Crítica.

No primeiro ponto, é apresentado o significado histórico da Revolução Russa que não pode ser separada da revolução burguesa, no interior das quais se deu o surgimento das classes fundamentais do capitalismo, a partir de onde se forjaram as lutas do proletariado contra a exploração capitalista. O texto compartilha do entendimento de que a Revolução Bolchevique foi um fato fundamental para história do Século XX, notadamente como referência ao proletariado, tal qual o foi a Revolução Francesa para demarcar o fim do antigo regime e a vitória política da burguesia revolucionária. Em seguida, no segundo item, faço uma leitura da educação na primeira fase da Revolução de Outubro, estudando-se o relatório apresentado no I Congresso de Toda a Rússia para a Instrução Pública, denominado "A Educação na Rússia Revolucionária”, ocorrido em 1922, pelo Presidente do Comissariado do Povo para a Instrução Pública, Anatóli Lunatcharski, que descreveu as questões fundamentais da educação no contexto da revolução. Finalmente, na terceira e última parte, traço feitas algumas observações sobre as possíveis contribuições da educação na Rússia revolucionária no processo de construção da Pedagogia Histórico-Crítica.

\footnotetext{
2 É absurda a ideia de um autor "autoplagiar-se", pois não faz o menor sentido que um intelectual não se aproprie de seus próprios escritos anteriores.
} 


\section{O significado histórico da Revolução Russa}

O significado histórico da Revolução Russa não pode ser desligado da Revolução Industrial, do surgimento das classes fundamentais do capitalismo, das lutas dos trabalhadores contra a exploração capitalista, das lutas de classe dos anos 1840, que levaram à criação do Partido Comunista, das lutas de classe dos anos 1870, que desembocaram na Comuna de Paris, marcando na história que 1871 foi a primeira vitória dos trabalhadores que, por um período efêmero, fez com que as massas de trabalhadores, camponeses e miseráveis aprendessem que é possível a tomada do poder político. Contraditoriamente, esse movimento foi acompanhado pelo fortalecimento da máquina do Estado burguês, notadamente a segurança do capital e a máquina de guerra e repressão.

Sobre a Revolução Russa não havia, entre os clássicos marxistas e bolcheviques, consenso quanto às possibilidades que a revolução ocorresse nessa formação social. A leitura dos clássicos parece induzir ao prognóstico da revolução proletária como alternativa líquida e certa, com a instalação de um governo socialista, somente numa sociedade de capitalismo avançado, decorrência do pleno desenvolvimento social das forças produtivas, barrada por relações de produção privatistas. Contraditoriamente, porém, a Revolução ocorreu numa formação social de revolução capitalista tardia, uma sociedade rural e ainda com características fortemente feudais, com um governo monárquico e absolutista!

Parecem brincadeiras de Clio que precisava entender a transformação histórica por suas contradições, pela negação-da-negação, e que para isso forjou, no seio das contradições da totalidade histórica russa, a primeira revolução socialista da história!

Não é necessária uma longa exposição sobre a Revolução de Outubro de 1917 e, menos ainda, sobre a importância e o significado que representou no âmbito da história contemporânea, tema que foi trabalhado por muitos pesquisadores. Por isso, apenas irei me posicio- 
nar quanto ao entendimento que tenho da importância histórica da Revolução Soviética. Para tanto, poderia recorrer a muitos autores para caracterizar o que penso sobre o assunto, mas novamente recorro à boa escrita totalizante de Eric Hobsbawm, em seu $A$ Era dos Extremos (2003), assinalando que compartilho com o historiador marxista o entendimento da Revolução Bolchevique como fato fundamental para história do Século XX, tal qual o foi a Revolução Francesa para demarcar o fim do antigo regime e a vitória política da burguesia revolucionária.

Para Hobsbawm, o Breve Século XX nasceu sob a égide de uma nova força: a Revolução em escala mundial, sendo a Revolução Russa uma filha dileta das guerras desse Século, transformando uma sociedade local e feudalizada em uma superpotência mundial (ibidem, p. 61). A revolução de outubro foi universalmente reconhecida como um acontecimento que abalou o mundo. Foi a fonte inspiradora de amplos movimentos políticos, produzindo uma onda de rebeliões em todo mundo que, acompanhando os movimentos contraditórios da história, colocava na ordem do dia a possibilidade de se realizar a utopia da emancipação universal - a construção de uma sociedade sem classes, sem opressão, sem desigualdades e sem injustiça (ibidem, p. 78). A Revolução Russa provocou uma série de movimentos por todo o mundo, como as guerrilhas, as insurreições, a descolonização de países que, ainda no século XX, estavam dominados por impérios coloniais.

Em uma era de profundas contradições, enquanto a revolução bolchevique impulsionava politicamente o movimento proletário, reorganizando a produção e promovendo pleno desenvolvimento econômico, o capitalismo desmoronava em profunda e grave crise estrutural. Como consequência, “a grande depressão destruiu o liberalismo econômico por meio século... obrigou os governos ocidentais a dar às considerações sociais prioridade sobre as econômicas em suas políticas de estado" (ibidem, p. 99). Hobsbawm é testemunha que, enquanto o mundo capitalista vivia profunda depressão, um país que havia rompi- 
do clamorosamente com o capitalismo, parecia imune à crise estrutural (ibidem, p. 100), surgindo o regime soviético como uma alternativa de economia racional e planificada face ao fracasso das democracias liberais e à política do laissez faire.

É esse o entendimento que tenho sobre a importância da Revolução Russa para a história da humanidade: foi o marco da construção de uma sociedade socialista para o proletariado, da mesma forma que a Revolução Francesa foi o marco da tomada do poder pela burguesia. Foi isso o que lapidarmente registrou Hobsbawm:

[...] pela primeira vez na história o problema da construção de uma sociedade socialista deixou de ser abstrato. Como a União Soviética permaneceu até o final da Segunda Guerra Mundial como o único Estado dirigido por marxista, a discussão deste problema se referia predominantemente àquele país ou se desenvolvia em torno dele. $\mathrm{E}$ esta discussão continuou por muito tempo a ser dominada pela experiência soviética, estando ainda em grande parte ancorada naqueles mesmos termos, uma vez que os esforços subsequentes para construir o socialismo se modelaram segundo o exemplo da URSS como ponto de referência essencial (HOBSBAWM, 1985, p. 16).

\section{A educação na Revolução de Outubro}

A Revolução de Outubro não se deu sem o enfrentamento de uma forte onda contrarrevolucionária na Rússia e fora dela. Além da luta armada levada a cabo pelo Exército Vermelho, foi necessário um amplo trabalho de esclarecimento das massas, uma ampla ação de formação dos trabalhadores do campo e da cidade, possibilitando a compreensão dos fundamentos de uma nova sociedade composta por homens desalienados, preocupados com a busca do bem comum, superando o individualismo e o egoísmo.

Era necessária uma ampla educação das massas, tirando-as do analfabetismo e da ignorância. Essa tarefa - o combate ao analfabetismo - foi considerada fundamental pelos dirigentes bolcheviques. Nes- 
se processo a escola emergiu como uma instituição necessária e imprescindível. Sabiam os revolucionários russos que a produção social de novas relações sociais exigia uma escola voltada à formação do novo homem que a nova sociedade socialista necessitava. Sabiam os revolucionários soviéticos que a escola era uma arma fundamental nas mãos das classes dirigentes (PISTRAK, 2005, p. 30) e, por isso mesmo, era necessário colocá-la a serviço da construção da nova ordem socialista. Sabiam que a revolução e a escola deveriam agir paralelamente "porque a escola é a arma ideológica da revolução" (idem, ibidem).

Foi assim que, ainda no contexto da luta revolucionária, o coletivo de educadores revolucionários, compreendendo a importância do papel histórico da escola na formação do novo homem, tomou para si a tarefa histórica de construção de uma pedagogia e uma prática revolucionária. Krupskaya, Shulgin e Pistrak e muitos outros educadores tinham claro que a escola deveria ter como função:

[...] a formação de um homem que se considere um membro de uma coletividade internacional construída pela classe trabalhadora em luta contra um regime agonizante e por uma vida nova, por um novo regime social onde as classes não existam mais. Em termos mais concretos, é preciso que a nova geração compreenda, em primeiro lugar, qual é a luta travada atualmente pela humanidade; em segundo lugar, qual é o espaço que deve ser ocupado por cada adolescente; e finalmente, é preciso que cada um saiba, em seus respectivos espaços, travar a luta pela destruição das formas inúteis, substituindo por um novo edifício (PISTRAK, 2005, p.31).

Lênin tinha plena consciência da importância da educação na luta pela consolidação do regime e, por ocasião do VIII Congresso do Partido Bolchevique, realizado entre os dias 18 e 23 de março de 1919, se empenhou para que fosse aprovada uma resolução que instituísse a instrução geral e politécnica gratuita, obrigatória para todas as crianças e adolescentes, totalmente laica e livre de influência religiosa, promotora de um ensino articulado com o trabalho socialmente produti- 
vo e formador de homens plenamente desenvolvidos para a sociedade comunista em construção (BITTAR e FERREIRA JÚNIOR, 2011). Era a aprovação, como política de Estado, da concepção marxista de educação. Essa concepção, partilhada pelos educadores revolucionários (cf. FREITAS, 2009, p. 11), foi assumida logo após a tomada do poder, com as medidas organizativas necessárias para a criação de um novo sistema educacional e uma nova escola, pois sabiam que a velha escola czarista, de caráter elitista e verbalista, não lhes servia nessa nova caminhada (PISTRAK, apud FREITAS, 2009).

Os revolucionários soviéticos sabiam que o reconhecimento da importância da escola, implicava na consciência dos limites da escola no contexto revolucionário. Por isso mesmo, era preciso diferenciar a pedagogia revolucionária das correntes pedagógicas democrático-burguesas que defendiam que somente através da escola, pela via pacífica, é que se poderia realizar a felicidade da humanidade. Diferente desses, os revolucionários deram à escola "um papel auxiliar no contexto de todo um processo suscitado unicamente pela vontade dos trabalhadores" (PISTRAK, 2005, p.113). Melhor dizendo, a escola deveria ter seu trabalho articulado com outras instituições, também responsáveis pela cultura na revolução.

No que diz respeito à organização bolchevique, após a tomada do poder pelos bolcheviques, foram criados os Comissariados do Povo, substituindo a antiga estrutura ministerial. Para a educação e a cultura foi criado o Comissariado do Povo para a Instrução Pública (NarKomPros), em 26 de outubro de 1917, sob a presidência de Anatóli Lunatcharski e que o presidiu de 1917 a 1929, com a responsabilidade de cuidar de toda a vida cultural da Rússia revolucionária e tendo como principal finalidade reconstruir o sistema educacional da Rússia (cf. FREITAS, 2009). Além de Lunatcharski, figuravam como membros do NarKomPros: Krupskaya, M. N. Pokrovskiy, Lepshinskiy, Pistrak, Blonski entre outros. Ainda em 1917, esse Comissariado elaborou o documento "Princípios Fundamentais da Escola Única do Trabalho", base da "Declaração sobre a Escola Única do Trabalho", aprova- 
da pelo Comitê Central do Partido Bolchevique, em 30 de setembro de 1918.

Nos primeiros anos de atuação do NarKomPros, foram muitos os desafios enfrentados, entre os quais se destacam: o combate ao analfabetismo, a organização de bibliotecas populares, a criação da imprensa educacional, a formação de professores, a organização da Juventude, a articulação do ensino com o trabalho produtivo etc. Esses desafios deveriam ser enfrentados com base numa educação fundada no marxismo e que implicava na abolição da herança da antiga escola czarista, com seus manuais impregnados da ideologia burguesa, dos métodos adestradores, tendo ainda que quebrar a resistência de um corpo docente conservador e defensor de uma concepção educacional tradicional. Em oposição à concepção pedagógica tradicional, era preciso introduzir na nova escola revolucionária, com novos conteúdos e novos métodos de ensino que deveriam ligar a escola à vida, ao trabalho e à população (SAVIANI, 2010).

É isso o que depreendo da leitura do relatório apresentado no $I$ Congresso de Toda a Rússia para a Instrução Pública, denominado “ $A$ Educação na Rússia Revolucionária”, ocorrido em 1922, no qual Lunatcharski descreveu o contexto educacional encontrado pelo Comissariado do Povo para a Instrução Pública: um "reino de analfabetismo" gritante, fruto da política de classes desenvolvida pelo regime czarista. O relatório assim registrou essa situação:

O primeiro objetivo que se coloca o governo da classe dominante consiste em manter o atraso das massas, para abafar todo o pensamento crítico. Quando se trata de um país como a Rússia, o ministro da Instrução Pública foi até o fim do regime czarista... ministro do obscurantismo público. Se uma sociedade quiser abrir uma escola, o ministro não dará autorização; Quando se quiser abrir uma universidade numa cidade, o ministro opor-lhe-á uma recusa; se um professor for talentoso, será exilado para o estrangeiro; se os estudantes lutarem para que a escola dê mais tempo aos estudos científicos, mandam-se para a tropa. Foi esta a constante da política do Ministério 
da Instrução Pública que era uma espécie de departamento do Ministério do Interior. Este velava por conservar a sua preponderância sobre a escola (LUNATCHARSKI, 1922, p. 34).

O Comissário da Instrução Pública foi enfático ao afirmar que a escola ainda era, para a grande maioria da população, uma realidade inacessível, apresentando dados sobre a situação encontrada:

Sabeis que, globalmente falando, as nossas escolas do primeiro grau só podem receber metade das crianças, e que o segundo grau é apenas suficiente para 5 a $6 \%$ das crianças. Fica, pois, claro que cerca de nove pessoas em cada dez não podem, no término do primeiro grau, entrar para o segundo grau. E isso desfavorece enormemente a população rural em relação à urbana, o que destrói a própria unidade relativa da escola. Daí resulta que, apesar de tudo, um filho de camponeses terá, nessa qualidade, na maioria dos casos e independentemente das suas capacidades - isto na Rússia soviética, mesmo que à escola sejam garantidas as melhores condições nas próximas décadas após a revolução - muito menos possibilidades de ser admitido no segundo grau que a criança da cidade (ibidem, p. 49)

O Partido Bolchevique assumiu as propostas dos pais do marxismo para a educação, defendendo a Escola Única do Trabalho, a escola unitária que deveria promover uma profunda imbricação entre trabalho e educação, visando uma formação omnilateral do homem. A escola socialista deveria se constituir na escola do trabalho, uma escola que deveria ter por objetivo o pleno desenvolvimento de todas as capacidades e potencialidades do educando, introduzindo os processos de trabalho de modo prazeroso, como na brincadeira, pouco a pouco passando dos processos simples de trabalho aos mais complexos e produtivos, proporcionando aos educandos o domínio dos conhecimentos teóricos e práticos. Uma escola ativa, no sentido de alimentar os conhecimentos a partir dos interesses dos alunos, assimilados por todas as capacidades do organismo (ibidem, p. 64). 
Em síntese, essa proposta da escola do trabalho era a própria escola politécnica e que deveria possibilitar não um conhecimento limitado e parcial ao educando, mas uma aprendizagem de tantos e quantos conhecimentos necessários à produção de um grande centro de produção industrial; o máximo de conhecimentos sobre as relações necessárias à vida do homem, bem como sobre a história da própria produção industrial, pois não existe conhecimento que não esteja ligado às relações entre o homem e a natureza, às relações que a produção industrial estabelece com a produção das matérias-primas e de tudo o que é necessário à produção da existência humana (ibidem, p. 65).

Entendiam perfeitamente bem os educadores revolucionários que, sob a revolução do trabalho, era necessário criar a escola do trabalho, única, mas não uniforme, em vista das diferenças regionais e das relações entre campo e cidade. A escola do trabalho era uma necessidade imperativa do pleno desenvolvimento do modo de produção socialista, então em implementação na URSS, onde o trabalhador era, simultaneamente, trabalhador e dono dos meios de produção (cf. AMBONI, BEZERRA NETO e BEZERRA, [ s.d.]).

Não havia muitas dúvidas quanto ao que deveria ser priorizado pelo NarKomPros, com a priorização e desenvolvimento de uma ampla campanha de alfabetização. René Capriles assim registra o empenho na alfabetização:

O Comissariado do Povo para a instrução Pública, desde seus primeiros dias, teve como meta conseguir a alfabetização geral e a educação política da população. Mas a própria sombra do analfabetismo impediu, nos primeiros anos, uma decisiva participação das massas na construção ativa do socialismo. No final de 1918 foi assinado o decreto "Sobre a mobilização dos que sabem ler e escrever", segundo o qual toda a população culta ficava compromissada com o trabalho da instrução geral. Lênin assinou, no dia 26 de dezembro de 1919, o decreto "Sobre a liquidação do analfabetismo", que obrigava toda a população com idade compreendida entre os 8 e os 50 anos, que não sabia ler nem escrever, a se alfabetizar na língua materna ou na rus- 
sa, conforme o desejo de cada um (CAPRILES, 2007, p. 30).

Completa o autor que:

O Estado Soviético não só obrigou as pessoas a estudar, mas também criou todas as condições necessárias para que isso acontecesse. Por exemplo: para todos os que estudavam, a jornada de trabalho foi reduzida em duas horas diárias com completa conservação do salário. Era permitido aproveitar as Casas do Povo, igrejas, clubes, casas particulares e locais adequados na fábrica, empresas e repartições soviéticas para dar aula (CAPRILES, 2007.p, 30-31)

Esse compromisso do Estado soviético com o combate do analfabetismo em todo o território russo resultou em que "[...] mais de 50 milhões de analfabetos e cerca de 40 milhões de semianalfabetos" fossem alfabetizados entre 1923 a 1939 (BITTAR e FERREIRA JÚNIOR, 2011, p. 390).

Objetivando a formação do novo homem e da nova mulher para a edificação da sociedade socialista, também era imprescindível a transformação de todo o sistema estatal de educação russo. Para tanto, já em 1918, o Comissariado Nacional "anunciava na primeira sessão de professores internacionalistas, a criação das escolas experimentais e demonstrativas, dentre elas, as Escolas-Comunas" (FREITAS, 2009, p.12-13). Estas escolas experimentais funcionaram como internato no período compreendido entre 1918 e 1937, quando foram definitivamente fechadas pelo governo stalinista. O objetivo principal das Escolas-Comunas, até 1925, foi de elaborar uma nova pedagogia para a escola do trabalho, com um novo currículo e um programa educacional orientador do trabalho pedagógico a ser desenvolvido em todas as escolas do território soviético (idem, ibidem).

Foi nesse contexto que foram definidos os princípios da Escola-Comuna: a autodireção; a participação direta de todo o coletivo nas diferentes formas de trabalho produtivo e intelectual da nova escola; o autosserviço; o desenvolvimento do trabalho produtivo - colocado 
como fator principal e base de toda a atividade escolar (ABREU, 2015, p. 338). Nessa direção, a experiência desenvolvida por Pistrak na Escola de Lepechinsky, foi uma das primeiras experiências de educação comunista. Para a construção de sua proposta de educação escolar, Pis trak considerou de importância fundamental a relação entre teoria e prática no processo de formação de professores: "Sem teoria pedagógica revolucionária, não poderá haver prática pedagógica revolucionária” (PISTRAK, 2009, p. 24).

Foram princípios básicos da experiência pedagógica de Pistrak: o trabalho como concepção educativa; o ensino organizado por complexo temático; a auto-organização dos estudantes e a participação direta de todo coletivo escolar nas decisões da instituição. Eram princípios que presentes no currículo, articulado ao plano individual de estudos dos educandos, com o objetivo de desenvolver o espírito científico nos alunos e, simultaneamente, a valorização do trabalho e o desenvolvimento da vida coletiva.

Explica Freitas (2009) que o ensino organizado por complexo temático buscava articular as diferentes ciências no currículo, visando desenvolver nos educandos a compreensão da realidade na sua totalidade. Todos os componentes curriculares deveriam ser articulados, visando possibilitar ao educando o pleno domínio dos conhecimentos científicos, devendo conter: 1 . o plano sistemático de cada disciplina ligado às disciplinas subjacentes; 2 o método de trabalho temático; 3 . o planejamento dos estudos obrigatórios e também para o trabalho em círculos, nos quais deveriam ser incluídas as atividades científicas e artísticas; 4 . a pesquisa, desenvolvida desde a mais tenra idade; 5 . o plano de estudo com meta, colocando como tarefa a assimilação de um mínimo definido, verificando em um tempo mais ou menos definido por formas que respondam ao caráter de cada disciplina (FREITAS, 2009). 


\section{Breves observações sobre a educação revolucionária e a Pe- dagogia Histórico-Crítica}

Penso que Dermeval Saviani deu uma contribuição fundamental para a construção de uma pedagogia a um só tempo histórica e crítica, com sólida fundamentação no marxismo, notadamente em Marx e Gramsci, também se referenciando em outros autores que, desde a concepção materialista dialética da história, contribuíram para o avanço de uma pedagogia crítica e revolucionária, referenciando: Bogdan Suchodolski, Mario Alighiero Manacorda e Georges Snyders. Além desses autores, situados no âmbito da Filosofia da Educação, também aparecem os nomes de Pistrak e Makarenko e da psicopedagogia da Escola de Vigotski (SAVIANI, 2003, p. 147-148).

Não há como e porque cobrar de Saviani o estudo e a incorporação dos educadores e pedagogos responsáveis pela construção de uma pedagogia revolucionária após a vitoriosa Revolução de Outubro. Considerando, porém, a pedagogia histórico-crítica como uma construção coletiva, coloquei-me o desafio de tecer algumas contribuições teóricas e práticas para a PHC e que surgiram da atuação de pedagogos e educadores do Comissariado do Povo para a Instrução Pública (LOMBARDI, 2017). Basicamente, como educador que se coloca o desafio de ensinar-e-aprender, perguntei-me: qual a contribuição dos pedagogos revolucionários à pedagogia histórico-crítica?

A leitura do já referenciado relatório - intitulado " $A$ Educação na Rússia Revolucionária” - do coletivo do Comissariado do Povo para a Instrução Pública, apresentado pelo Presidente do NarKomPros, Anatóli Lunatcharski, no I Congresso de Toda a Rússia para a Instrução Pública, ocorrido em 1922, trouxe à tona várias questões que nos ajudam a entender a organização de uma educação revolucionária e que se destina à formação intelectual, cultural e política dos trabalhadores do campo e da cidade, preparando homens novos que conduzam o parto da nova sociedade. 


\section{Em $1^{\circ}$. Lugar está a luta pela escola como uma prioridade para}

a revolução. Como antes da revolução não havia boas escolas na Rússia, mas uma antiga escola que mutilava as pessoas, isolando-as umas das outras, transmitindo conhecimentos inúteis que logo eram esquecidos (LUNATCHARSKI, 1922, p. 20), era necessário, com a revolução vitoriosa, organizar uma grande massa de conhecimentos para saber o que é preciso demolir e como fazê-lo. Para Lunatcharski, a luta pela escola foi uma das condições fundamentais para instruir o povo na direção de organizar e gerir uma vida estatal e política justa: "sabemos que de modo nenhum o povo pode organizar uma vida estatal e pública justa, nem verdadeiramente gerir a economia, se não for instruído, se não possuir todos os conhecimentos indispensáveis" (ibidem, p. 2). Numa perspectiva revolucionária, é preciso reorganizar a escola, pois esta é um instrumento fundamental para a formação política das massas, para o cumprimento de seu papel de organização da propaganda das ideias sociais de cooperação revolucionária (ibidem, p. 8) e para a formação de uma comunidade em que todos os homens busquem o bem de todos (ibidem, p. 13).

Em oposição à escola dual, que visava formar duas classes sociais, uma vivendo do trabalho intelectual e a outra do trabalho manual, um $2^{\circ}$. ponto que gostaria de sublinhar a criação da Escola Única como Escola do Trabalho, tema que foi aprofundado por Gramsci e que é referenciado por Saviani. Esta deveria promover a articulação do trabalho necessário à produção da existência, simultaneamente ao ensino da técnica no seu conjunto, do trabalho como meio de educação, do trabalho como participação do aluno no processo geral do trabalho da população (ibidem, p. 6). A escola unitária deveria estabelecer profunda relação entre trabalho e educação, para a formação omnilateral do educando. Tratava-se de implantar a escola comunista:

A escola que o comunismo traz com ele é antes de mais a escola única, isto é, a mesma para todas as classes sociais, utilizando em todo o lado os mesmos métodos de ensino. [...] Em segundo lugar, é uma escola do trabalho. Entendemos por isso uma escola que, tanto 
quanto possível, renunciasse a todas as "lições", que desse à criança desenvolvendo ao mesmo tempo as suas capacidades - a possibilidade de se desenvolver brincando, passando pouco a pouco dos processos simples de trabalho aos cada vez mais complexos e produtivos que proporcionam conhecimentos práticos. Ao alimentá-la sempre com os seus próprios interesses, a escola terá mais a certeza de levar a criança para o círculo dos conhecimentos e aptidões práticas, porque são assimilados pelos órgãos externos de todo o organismo (ibidem, p. 64).

Essa escola do trabalho era, em síntese, a escola politécnica:

Chamamos-lhe escola politécnica, porque não gostaríamos que o trabalho fosse estudado com base num só exemplo. Ao estudardes a história da fábrica, estais a estudar a evolução das relações de trabalho, aprendeis o que são as doenças profissionais, confrontar-voseis com a higiene social, a anatomia, a fisiologia - com as disciplinas médicas em geral. Não existe um grupo de conhecimentos que não esteja estreitamente ligado a essa gigantesca meada das relações entre o homem e a natureza, a esse nó que um grande centro industrial, uma fábrica ou uma oficina constituem [...] (ibidem, p. 65).

Para os educadores revolucionários a revolução do trabalho colocava a necessidade de se criar a escola do trabalho, única, mas não uniforme, em vista das diferenças regionais e das relações entre campo e cidade. Uma escola que efetivamente formasse os educandos para a vida, para o trabalho e para a administração pública.

Uma dimensão que mantém atualidade é o currículo e a organização do conteúdo, o $3^{\circ}$. aspecto que gostaria de ressaltar. Para os educadores revolucionários não era necessário mudar as matérias no programa escolar, pois sempre havia possibilidade de reagrupá-las e unificá-las em determinados centros temáticos. Para os pedagogos revolucionários, o problema não estava na forma, mas no conteúdo. $\mathrm{E}$ nesse sentido, efetivamente, a única matéria de estudo é a cultura humana, pois esta também engloba as ciências naturais (ibidem, p. 6). 
Em outras palavras, para os educadores soviéticos o problema não estava na denominação das matérias, mas em seu conteúdo, conforme se pode constatar na citação que segue de Lunatcharski em seu relatório:

Mas em que medida o conteúdo em si do conhecimento científico pode influir na instrução comunista das massas? As ciências naturais são as menos discutíveis. Decorrente da própria natureza do regime capitalista, os fundamentos da concepção do mundo, baseada nas ciências da natureza, devem ser mais ou menos objetivas. Como querem vocês, que consciente ou inconscientemente, seja falsificada a ciência sobre as plantas, os animais, sobre as leis da mecânica etc., se essa falsificação da verdade torna impossível gerir a economia? Já que é preciso gerir a economia, já que é preciso que as máquinas funcionem corretamente, já que é preciso curar o gado doente e beneficiar os solos, há necessidade de conhecimentos objetivos. [...] Completamente distinto é o que se passa nas ciências sociais. Aí tudo é extremamente discutível. Porque segundo a ideia que o homem se faz da história, segundo o que ele entende ser o seu ideal o que ele atribui importância como fator essencial da sua vida presente, disso depende a orientação desse homem na vida, o que ele vai fazer, como vai trabalhar (ibidem, p. 26).

Ainda que aparentemente não hajam problemas nas ciências da natureza, mas apontem a ideologização que ocorre nas ciências do homem, sabiam perfeitamente bem que as ciências não são neutras. Sob o regime burguês a ciência burguesa "teve de travar uma luta de morte com a jovem ciência do proletariado" e nessa luta a ciência burguesa teve que falsificar e alterar os dados "em proveito da classe dominante". Com a revolução proletária, era preciso recolocar a ciência em uma perspectiva do proletariado, o que não era tarefa simples: para isso é preciso um "trabalho muito intenso para formar o docente de ciências sociais de novo tipo" (ibidem, p. 27). Entendiam os revolucionários que "serão mantidas no programa escolar as mesmas matérias que lá se encontram hoje”, mas será preciso reagrupar as matérias e 
unificá-las em determinados centros, sendo a cultura humana efetivamente a única matéria de estudos.

[...] Sabemos que na sua evolução histórica, a sociedade humana está indissoluvelmente ligada à natureza, que o trabalho é a raiz da qual nascem as ciências naturais, isto é, a concepção da natureza. A bem dizer, a cultura humana é a única matéria de estudo, porque engloba, também, as ciências naturais como reflexo da natureza na consciência dos homens em todos os estágios da sua evolução.

A história da cultura humana é inseparável da natureza. É a ciência que melhor estudamos, não há ciência que dela não derive [...] (ibidem, p. 6).

Além das disciplinas científicas e tecnológicas, também é necessária "a educação física” e que tem por finalidade: desenvolver o corpo... moldar o seu próprio corpo a fim de torná-lo ágil, são, belo"; além desta, também é preciso incluir "a educação estética" entendida "como o desenvolvimento das inclinações criativas do homem pela beleza" (ibidem).

Numa perspectiva revolucionária um $4^{\circ}$. aspecto é a Organização da gestão escolar que, da mesma forma que o poder do Estado, deve assentar-se em todo poder às massas. Em uma sociedade dividida em classes, a escola é organizada como a sociedade, com alguns que mandam e controlam e a maioria que obedece; é organizada como a produção, com a separação entre os que mandam e os que obedecem. $\mathrm{Na}$ sociedade classista não se organiza uma escola única e para todos e, por isso, a burguesia não pode aceitar uma escola única para todos, notadamente para a grande maioria da população - o trabalhador (ibidem, p. 5). Somente com a revolução, pela qual se buscou eliminar a divisão entre as classes, era possível pensar a criação de uma escola única, uma escola para todos. E nessa nova escola, era necessária a construção de uma administração que adotasse a mesma organização que a realizada no poder político: a autogestão completa e a organização de um poder popular (ibidem, p. 3). Era fora de questão, na Rússia 
revolucionária, organizar a escola com um caráter burocrático. Ao contrário, era necessário desmontar toda a velha estrutura, a começar pelo antigo Ministério da Instrução Pública e liquidar os restos do antigo aparelho escolar (ibidem, p. 4). Na nova escola é preciso organizar a gestão escolar buscando introduzir a autogestão, é preciso criar um Conselho Escolar (um Soviete Escolar) com a participação dos alunos, pais e professores (ibidem, p. 7).

Como a sociedade de classes criou organismos gestores à imagem e semelhança do Estado classista, numa perspectiva revolucionária é preciso educar as novas gerações numa perspectiva autogestionária, é preciso que os alunos assumam, eles próprios, o máximo de obrigações e responsabilidades. É desse modo que aprenderão a autogestão e mais ainda, deve ser concedida aos alunos "plena liberdade na organização das sociedades consagradas às ciências, à ginástica, à música, ao teatro, na criação de toda a espécie de revistas, de clubes políticos etc." e, nessas organizações, "É preferível que os docentes nelas não entrem para que a presença de adultos não perturbe as crianças na procura da sua própria via” (ibidem, p. 7)

Para além da transição socialista, os pedagogos revolucionários entendiam que a escola deveria formar efetivamente a todos para uma organização comunista do poder, através da autogestão e da organização coletiva em todos os níveis (os Sovietes). E a melhor forma da escola instruir nessa direção, era organizar a própria gestão escolar na perspectiva que se queria construir socialmente.

Finalmente, um $5^{\circ}$. aspecto a salientar é que uma educação que tenha por objetivo o homem como um ser social, a construção futura da sociedade comunista, não pode perder de vista que para isso é necessário que a escola se volte à formação individual. Essa questão surgiu no relatório de Lunatcharski que assim a registrou "Se perguntarem: e a individualidade, será ela admitida na vossa escola? Responderemos: com certeza" (ibidem, p. 14). Mas não se trata da mesma formação para a individualidade presente na concepção burguesa, mas uma concepção social da individualidade. 
Se alguém perguntar: quereis uma orquestra bem afinada, quereis atingir a máxima perfeição de harmonia, ides aceitar instrumentistas virtuosos? - Nem pode ser de outra maneira! A orquestra implica uma grande variedade de sons, supõe uma harmoniosa polifonia, em que tudo é unidade, e não uma partitura onde cada um faria o que lhe parecesse melhor, onde um se esforçaria por abafar a melodia do outro, ou por arrastá-lo na sua. Este tipo de orquestra contra-natura, demente, é a sociedade burguesa. Uma orquestra natural não consiste na consonância uniforme, mas numa sociedade social onde cada um toca o seu próprio instrumento. Alguém se ocupará de arte outro de ciência, um terceiro de técnica etc. Assim sendo, cada um terá acesso a tudo: não é músico, mas ouve música; um músico pode interessar-se por astronomia, saber como é confeccionado o vestuário etc. [...] (ibidem, p. 14).

Sublinha que para uma autêntica escola socialista, é fundamental a maior individualização, pois quanto mais "a criança se vá desenvolvendo [...] mais importante se torna que, desde a mais tenra idade, se lhe ensine a respeitar o caráter social de outrem, sejam organizados para as crianças jogos e passatempos comuns, sejam obrigadas a cooperar" (ibidem, p. 14). A escola revolucionária não pode ensinar o cada um por si, mas tem que formar para que cada um atue em conjunto, coletivamente. O teatro na escola, o trabalho no jardim escolar, ou numa fazenda, numa biblioteca, ou num laboratório, deverá ser meio que possibilite às crianças "trabalhar em conjunto", com o que não se formará cada um por si, para ocupar-se unicamente de si próprio, mas levará em conta os outros (ibidem, p. 14).

\section{Conclusão}

Busquei com o estudo das contribuições que a Revolução Russa trouxe para a educação, introduzir, para efeitos de reflexão, cinco pontos que trazem contribuições para a construção da pedagogia histórico-crítica. Em primeiro lugar, reforçando a importância da luta pela escola como uma luta revolucionária, pois a alfabetização é funda- 
mental para a formação política das massas e o aprendizado dos conteúdos dos saberes historicamente produzidos pela humanidade. Em segundo lugar, ainda que a organização escolar no Brasil (e em outras formações sociais) foi na direção de criação de tantas e quantas escolas quanto as classes e frações de classe, descrita como escola dual, há exemplos contemporâneos de construção de uma escola única, pública, gratuita, voltada ao atendimento de todos indistintamente. Na concepção que partilhamos com os revolucionários soviéticos, essa escola única deve se constituir como uma escola do trabalho - uma escola que introduza a todos no trabalho intelectual e no trabalho manual, no saber científico e no fazer produtivo dos diferentes bens que são necessários à satisfação das necessidades humanas. Em terceiro lugar, trago algumas reflexões sobre a organização do currículo escolar e de seu conteúdo. Não é preciso reinventar a roda, despendendo anos de trabalho com a elaboração de novos currículos para os diferentes níveis de ensino. Ainda que este seja um caminho necessário para recolocar sob novas bases o conteúdo escolar, o problema não está nas disciplinas e em sua organização curricular, mas na apropriação dos conhecimentos científicos pela burguesia, em seu próprio benefício. É fundamental que, na direção da construção de uma escola única, se busque possibilitar ao aluno o domínio dos conteúdos das diferentes disciplinas e que estes estejam articulados à produção e à solução de problemas sociais, ambientais e produtivos. A concepção de união do ensino com o trabalho, com a educação física, com a cultura e as artes mantém atualidade. É necessário que os educadores busquem não uma formação unilateral dos educandos, mas uma educação omnilateral. Em quarto lugar, entendo que essa nova escola precisa de uma nova concepção de organização e gestão escolar que, sendo na direção da determinação legal de democratização da escola, possibilite a criação de Conselhos Escolares que introduza, gradativamente, a autogestão escolar pela comunidade de educadores, alunos, pais de alunos e comunidade envolvente. A escola deve ser também formadora das bases e fundamentos da sociedade do futuro. Finalmente, um quinto ponto: a 
educação que objetivamos deve formar plenamente os indivíduos, isto é: a escola deve voltar-se a plena formação individual, mas não na perspectiva egoísta da individualidade como formadora da diferença, do "cada um por si e Deus por todos". A formação da individualidade é o reconhecimento que cada ser humano é membro único de um ser coletivo e que cada um contribui, a seu modo, para a formação e o pleno desenvolvimento do ser social. Para cumprir plenamente seu papel, a escola deve formar plenamente cada um a vida e atuação em conjunto, para o bem comum. Como numa orquestra e sua grande variedade de instrumentos e sons, a virtuosidade de cada do músico e seu instrumento não está em apagar a virtuosidade do outro músico e seu instrumento, mas em todos contribuírem a seu modo com uma harmonia polifônica.

Sou educador conhecido por minhas posições, sendo "figurinha carimbada" na reflexão marxista da educação. Desde essa perspectiva, defendo que, como educadores, precisamos estar comprometidos com a construção de um novo homem para uma nova sociedade. Se cada educador entender adequadamente a sua missão, ao entrar na sala de aula ou noutro espaço escolar, deve sentir que realiza algo de solene que deve fazer vibrar de alegria o seu coração, porque está vivendo o milagre da transfiguração da Humanidade (ibidem, p. 68). A citação vale a pena ser lida:

Mutilaram o homem, fizeram dele um funcionário e outros monstros, e agora é preciso fazer da criança uma maravilha, fazer dela um homem autêntico que tão raramente encontramos entre nós e os nossos pais, que deve tornar-se cada vez mais frequente entre os que são mais novos que nós, que o será ainda mais entre os nossos filhos e filhas e que se tornará um tipo dominante entre os nossos netos. Este milagre é a revolução, é a própria vida que o produz, mas sem pedagogos ele não pode acontecer. Este é o único prodígio que a ciência pode reconhecer: a transfiguração do homem (idem, ibidem, p. 68). 


\section{Referências}

ABREU, Malila da Graça Roxo. O legado educacional da transição russa: elementos para analise da política educacional do período pós-revolucionário. Revista HISTEDBR On-line, Campinas, nº 65, p.328343, out. 2015. Disponível em: <http://periodicos.sbu.unicamp.br/ojs/ index.php/histedbr/article/view/8642714 > Acesso em: 06 jul.2020.

ABREU, Malila da Graça Roxo. O Pensamento Pedagógico Socialista: reflexões sobre a experiência educacional desenvolvida na Rússia pósrevolucionária e suas contribuições para o projeto educacional da sociedade contemporânea. Dissertação (Mestrado em Educação), 182p. Faculdade de Educação. Universidade Federal do Maranhão, 2011 AMBONI, Vanderlei; Bezerra Neto, Luiz; Bezerra, Maria Cristina dos Santos. Trabalho e educação na construção da Rússia socialista. Disponível em: <http://www.estudosdotrabalho.org/texto/gt8/trabalho.pdf> Acesso em: 06 jul.2020.

BITTAR, Marisa; FERREIRA JR, Amarílio. A educação na Rússia de Lênin. Revista HISTEDBR On-line, Campinas, número especial, p. 377-396, abr/2011. Disponível em:

$<$ http://www.histedbr.fae.unicamp.br/revista/edicoes/41e/doc01 41e 2.pdf.> Acesso em: 06 jul.2020.

CALDART, Roseli Salet. “Apresentação”. In: PISTRAK, Moisey Mikhaylovich. Fundamentos da Escola do Trabalho. São Paulo: Expressão Popular, 2005.

CAPRILES, René. Makarenko: o nascimento da Pedagogia Socialista. São Paulo: Scipione, 2007.

FREITAS, L C de. A luta por uma pedagogia do meio. In: PISTRAK, M. M. A Escola Comuna. São Paulo: Expressão Popular, 2009. . “Apresentação”. In: PISTRAK, Moisey Mikhaylovich (org). A Escola-Comuna. São Paulo: Expressão Popular, 2009. 
. Moisey M. Pistrak. In: Historia Geral da Educação e da Pedagogia. Faculdade de Educação- FE- UNICAMP, 24 de set./2010. Videoconferência.

HOBSBAWM, Eric. História do Marxismo: São Paulo: Paz e Terra, 1985.

. Era dos Extremos: o breve século XX: 1914-1991. São Paulo: Companhia das Letras, 2003.

. Introdução ao Manifesto Comunista. In: Sobre a História: São Paulo: Companhia das Letras, 2006.

. Podemos escrever a história da Revolução Russa. In:

Sobre a História. São Paulo: Companhia das Letras, 2000.

KRUPSKAIA, N. Acerca de la Educacion Comunista - Articulos y Discursos. Traducido del ruso por V. Sanchez Esteban. Moscú. Ediciones en Lenguas Extranjeras. S/d.

. Diferencia entre La Instruccion Profesional y La Politécnica In: A cerca de la educacion comunista - Articulos y Discursos. Moscou: Edições em Lenguas Extranjeras, 1930

. El Movimiento de pioneiros como problema pedagógico In: A cerca de la educacion comunista - Articulos y Discursos, Moscou, Edições em Lenguas Extranjeras, 1927 . Importante Sector del Trabajo del Komsomol. In: A cerca de la educacion comunista - Articulos y Discursos.Moscou:Edições em Lenguas Extranjeras, 1935.

LÉNINE, V.I.. Sobre as Tarefas do Proletariado na Presente Revolução. 07 de abril de 1917. Disponível em: < https://www.marxists.org/ portugues/lenin/1917/04/04 teses.htm> Acesso em: 06 jul.2020

LOMBARDI, José Claudinei. Educação e ensino na obra de Marx e Engels. Campinas: Editora Alínea, 2011. 265 p.

. A revolução Soviética e a pedagogia histórico-crítica. In: ORSO, Paulo; Julia Malanchen e André Paulo Castanha (org.). Peda- 
gogia histórico-crítica, educação e revolução: 100 anos da revolução russa Campinas, SP: Autores Associados, 2017, 224 p.

LUNATCHARSKI, Anatoli. Decreto sobre la a educación popular. In. $<$ http://marxists.org/espanol/lunacha/obras/1917-11-11.htm > Acesso em: 06 jul.2020

MARX, Karl. Contribuição à crítica da economia política. 1859. In: <https://www.marxists.org/portugues/marx/1859/contcriteconpoli/introducao.htm\#topp $>$ Acesso em: 06 jul.2020

PISTRAK, M.M. Fundamentos da Escola do Trabalho. São Paulo: Editora Expressão Popular, 2005.

PROGRAMAS OFICIAIS. A educação na República dos Soviets. Tradução de Violeta Sandra. São Paulo: Companhia Editora Nacional, 1935.

SAVIANI, Dermeval e DUARTE, Newton (orgs.). Pedagogia histórico-crítica e luta de classes na educação escolar. Campinas, SP: Autores Associados, 2012.

SAVIANI, D. Escola e democracia. Campinas: Autores Associados, 2008. (Coleção Educação Contemporânea)

- Antecedentes, origem e desenvolvimento da pedagogia histórico-crítica. In: MARSIGLIA, Ana Carolina G. (org.). Pedagogia histórico-crítica: 30 anos. Campinas, SP: Autores Associados, 2011.

. Contextualização histórica e teórica da Pedagogia HistóricoCrítica. In: . Pedagogia Histórico-Crítica: primeiras aproximações. 8a. ed. revista e ampliada. Campinas, SP: Autores Associados, 2003.

SAVIANI, Nereide. Concepção socialista de educação: a contribuição de nadedja krupskaya. Revista HISTEDBR On-line, Campinas, número especial, p. 28-37, abr 2011. Disponível em: <http://www.histedbr.fe.unicamp.br/revista/edicoes/41e/art03 41e.pdf > Acesso em: 06 jul.2020 
. Educação e pedagogia na Rússia Revolucionária: o comissariado do povo. História Geral da Educação e da Pedagogia. Faculdade de Educação - FE-UNICAMP, 03 de set./2010. Videoconferência. 
